\title{
MALEZAS DOMINANTES EN LOS CULTIVOS DEL INSTITUTO DE INVESTIGACIÓN, PRODUCCIÓN Y EXTENSIÓN AGRARIA (INPREX) Y DEL CENTRO EXPERIMENTAL AGRÍCOLA (CEA) III "LOS PICHONES" TACNA - 2014
}

\author{
DOMINANT WEEDS IN CROPS RESEARCH INSTITUTE, PRODUCTION AND \\ AGRICULTURAL EXTENSION (INPREX) EXPERIMENTAL AND \\ AGRICULTURAL CENTER (CEA) -2014 III “LOS PICHONES" TACNA - 2014
}

${ }^{1}$ Rosario Zegarra Zegarra, ${ }^{2}$ Nelly Arévalo Solsol

\section{RESUMEN}

Cuando empleamos el término "Maleza", nos referimos a una planta que crece espontáneamente entre las cultivadas, comportándose como un fuerte competidor de una especie de valor económico. Su rusticidad, la fácil adaptación favorece la dominancia. Por otro lado generalmente los animales no las consumen y naturalmente esto favorece a su multiplicación masiva. El objetivo del presente trabajo es identificar, clasificar y describir las malezas existentes en los cultivos del Instituto de Producción y Extensión (INPREX) y Centro Experimental Agricola (CEA III) Los Pichones, los cuales forman parte de la Universidad Nacional "Jorge Basadre Grohmann" de Tacna. El presente trabajo de investigación es de carácter descriptivo explicativo. Se realizó un estudio "in situ" de las especies Se colectó material para procesarlo en el laboratorio. Se colectaron 28 especies de malezas. Las Magnoliopsidas (Dicotiledóneas) fueron el grupo más abundante con 23 especies, 16 géneros, y 11 familias. Las Liliopsidas (Monocotiledóneas) están representadas por 05 especies, 05 géneros y 02 familias. Las familias con mayor número de especies fueron las Asteráceas y Poáceas con 5 y 4 especies cada una.

Palabras clave: Malezas, Magnoliopsida, Liliopsida, especie, género, familia.

\section{ABSTRACT}

When we use the term "Weed", we refer to a plant that grows spontaneously between cultivated, behaving as a strong competidor of a species of economic value. Its hardiness, easy adaptation favors dominance. On the other hand, usually do not consume animals and naturally this favors its mass multiplication. The aim of this study is to identify, classify and describe existing weeds in crops of the Institute of Production and Extension (INPREX) and III Experimental Agricultural Centre (CEA)"Los Pichones", which are part of the National "Jorge Basadre Grohmann" University. The study is descriptive. A study "in situ" of the species was performed and material was collected for processing in the laboratory. 28 weed species were collected. The Magnoliopsida (Dicotyledons) were the most abundant group with 23 species, 16 genera and 11 families. The Liliopsidas (monocots) are represented by 05 species, 05 genera and 02 families. The most diverse families were Asteraceae (05), and Poaceae (4) species.

Keywords: Weed, Magnoliopsida, Liliopsida, specie, genero, familie.

\section{INTRODUCCIÓN}

Hay especies invasoras que pueden convertirse en malezas. Cuando empleamos éste término, nos referimos a una planta que crece espontáneamente entre las especies cultivadas, comportándose como un fuerte competidor de una especie de valor económico. Son especies rústicas que se adaptan fácilmente, lo cual favorece la dominancia.
Existen 350000 especies de plantas, de las cuales 2000 se consideran nocivas por sus características y comportamiento, causando cada año grandes pérdidas a la agricultura.

Las familias que presentan mayor número de ellas son: Poáceas, Ciperáceas y Asteráceas.

En el INPREX y en el CEA III Los Pichones, fundos de la Universidad Nacional "Jorge Basadre Grohmann", se cultivan diferentes especies, actividades realizadas por los

\footnotetext{
Doctora en Ciencias Biológicas, Bióloga. Docente de la Facultad de Ciencias Agropecuarias de la Universidad Nacional Jorge Basadre Grohmann. Tacna-Perú.

Doctora en Ciencias Ambientales. Ingeniero Agrónomo. Docente de la Facultad de Ciencias Agropecuarias de la Universidad Nacional Jorge Basadre Grohmann. Tacna-Perú.
} 
Zegarra, R. \& Arévalo N. Malezas dominantes en los cultivos del Inprex y del centro experimental agrícola (CEA) III "Los Pichones" Tacna - 2014.

estudiantes de la Escuela de Agronomía, como también por el personal destinado para tal fin. Entre ellos mencionamos Lycopersicon esculentum "Tomate" Chenopodium quinoa "Quinua" Phaseolus ulgaris "Vainita" Solanum melongena "Berenjena", Capsicum annutum "Ají páprika", Brassica oleraced" Brócoli", Cucurbita pepo var. Zucchini, Gossypium barbadense "Algodón", frutales y otros.

En éstos campos de cultivo se observan malezas, que compiten con los cultivos en forma directa por agua, luz, nutrientes y espacio, disminuyendo los rendimientos.

La importancia de éste trabajo de investigación, radica en el conocimiento de las malezas que interfieren directamente con las especies cultivadas. Para poderlas controlar es necesario reconocerlas en sus estados iniciales de crecimiento.

El objetivo general del presente estudio es la identificación, clasificación y descripción de las malezas.

\section{Características de las malezas.}

a. Se adaptan a diferentes medios ambientales, resistiendo mejor que las especies cultivadas a factores climáticos adversos como lluvias, sequía, ataque de insectos, parásitos vegetales, exceso de acidez, alcalinidad.

b. Producen grandes cantidades de semillas. La cantidad varía notablemente presentándose en algunas de ellas cientos, mientras que en otras sobrepasan 200000 semillas por planta. El tamaño de las semillas es pequeño y la mayoría son viables.

c. Reproducción vegetativa: Tubérculos, rizomas, estolones, bulbos, fragmentación de tallos etc.

d. Interfieren por alelopatía. El $90 \%$ de las malezas presentan ésta característica.

\section{Clasificación de las malezas}

a. Según el tipo de planta: Hoja angosta (Monocotiledóneas) y de hoja ancha (Dicotiledóneas)

b. Ciclo de vida: Anuales, bienales y perennes.

c. Hábitat: Terrestres y acuáticas.

d. Origen: Nativas e introducidas

\section{Pérdidas ocasionadas por las malezas}

a. Aumentan costos de producción

b. Causan pérdidas por la baja calidad de los productos.

c. Disminución del rendimiento de cultivo

d. Hospedantes de plagas y agentes patógenos.

e. Disminuye el valor de la tierra.

f. Dificultan las cosechas.

g. Dificultan el manejo de las aguas.

h. Afectan la salud humana y de los animales.

i. Pueden crear híbridos, originando descendientes indeseables.

\section{Dispersión de las malezas}
a. Por acción del viento (Anemocoria)
b. Poracción del agua (Hidrocoria)
c. Por acción de los animales (Zoocoria).
d. Por acción del hombre (Antropocoria)

\section{MATERIALES Y MÉTODOS}

El presente trabajo de investigación es de carácter descriptivo-explicativo. Son variables de estudio las características botánicas de las malezas, y su sistemática.

Se realizaron colectas en el INPREX y (CEA III) Los Pichones, en el año 2014. Se tomaron fotos "in situ".

La metodología a seguir fue: Identificación, clasificación y descripción de las malezas.

La identificación se realizó en base a claves, revisión bibliográfica, material de herbario.

Los materiales empleados fueron: Tijeras de podar, libreta de campo, bolsas de polietileno, papel toalla, regla, lápiz. dora.

Equipos utilizados: Cámara fotográfica, computa-

\section{RESULTADOS}

En el INPREX y en el CEA III Los Pichones existen especies cultivadas tanto anuales como perennes.

Los alumnos de pregrado y posgrado realizan sus trabajos de tesis en diferentes especies cultivadas: Hortalizas, frutales y ornamentales.

Las malezas invaden sus cultivos, teniendo que realizar un control de ellas. Los deshierbos se realizan en todo momento en forma manual, con la finalidad de dar a las plantas cultivadas mejores condiciones para su buen desarrollo, evitando que las malezas compitan por nutrientes, agua, luz, espacio.

Las malezas son plantas que crecen donde no son deseadas, son persistentes, generalmente no tienen valor económico, interfieren con el crecimiento normal de los cultivos y pueden afectar a los animales y al hombre.

En ellos se han encontrado 33 especies de malezas, presentes en los cultivos de: Arveja, orégano, habas, palto, maíz, rocoto y vainita (CEA III Los Pichones) y en cultivo de vid, durazno y olivo (INPREX)

\section{Tratamiento sistemático}

\section{a. Malezas de hoja angosta (Monocotiledoneas)}

\section{FAMILIA CYPERACEAE}

\section{Cyperus rotundus L. "Coquito"}

Especie perenne. Raíces con bulbos, tubérculos y rizomas. Tallos trígonos, lisos, de 15 a $30 \mathrm{~cm}$ de alto. Hojas numerosas, basales, graminiformes, margen liso, $15-20 \mathrm{~cm}$ de largo.

Inflorescencia: Antela de color púrpura. Simple o compuesta, con 5 ó 6 brácteas foliáceas, a menudo tres de ellas más largas que la anteras, alcanzando $12 \mathrm{~cm}$ de largo. Espiguillas aplanadas oblongas o linear-lanceoladas, con hasta 30 flores. oscuro.

Fruto: Aquenio trígono, ligeramente obovado, pardo

Nativa de Asia (India).

Frecuente en cultivos del INPREX.

Especie difícil de erradicar. Esta maleza ha sido 




Figura 1. Cyperus rotundus "Coquito"

reconocida como la más dañina a nivel mundial. Considerada como la maleza más importante del mundo.

\section{FAMILIA POACEAE}

\section{Bromus catharticus Vahl "Cebadilla"}

Especie anual, bianual o perenne, de 0,40 a $1 \mathrm{~m}$ de altura, hoja plana, Vaina generalmente pubescente. Lígula membranácea.

Inflorescencia en panoja laxa, amplia. Espiguillas de 2-5,6-12 floras.

Fruto: Cariópside linear-lanceolado.

Origen: Especie sudamericana.

Se cultiva en países templados de todo el mundo, para forraje.

Especie presente en cultivos del INPREX

\section{Cynodon dactylon (L.) Pers. "Grama dulce" "Pata de gallina"}

Planta perenne, rizomatosa y estolonífera. Cañas floríferas hasta $40 \mathrm{~cm}$ de alto. Láminas planas o plegadas. Lígula brevísima.

Inflorescencia formada por 4-8 espigas digitadas, en la extremidad de las cañas. Espigas unilaterales. Las espiguillas con glumas desiguales.

Fruto: Cariópside comprimido.

Origen: África tropical, en la actualidad cosmopolita.

Especie muy común en cultivos de orégano, maíz en el CEA III Los Pichones.

En regiones arenosas contribuye a consolidar el suelo. Se puede cultivar como forrajera, pero debe emplearse con cuidado porque es una planta cianogenética.

Es la segunda maleza más importante del mundo.

\section{Leptocbloa uninervia (Presl) "Pajilla"}

Especie anual, de $30-80 \mathrm{~cm}$ de alto, escasamente ramificada. Láminas planas. Lígula membranácea, laciniada.

Inflorescencia en panoja. Espigas numerosas. Espiguillas plurifloras, unilaterales, cilíndricas.

Fruto: Cariópside comprimido dorsalmente, elíptico, castaño.

Nativa de América.

Presente en cultivos de palto, arveja, rocoto (CEA III Los Pichones)

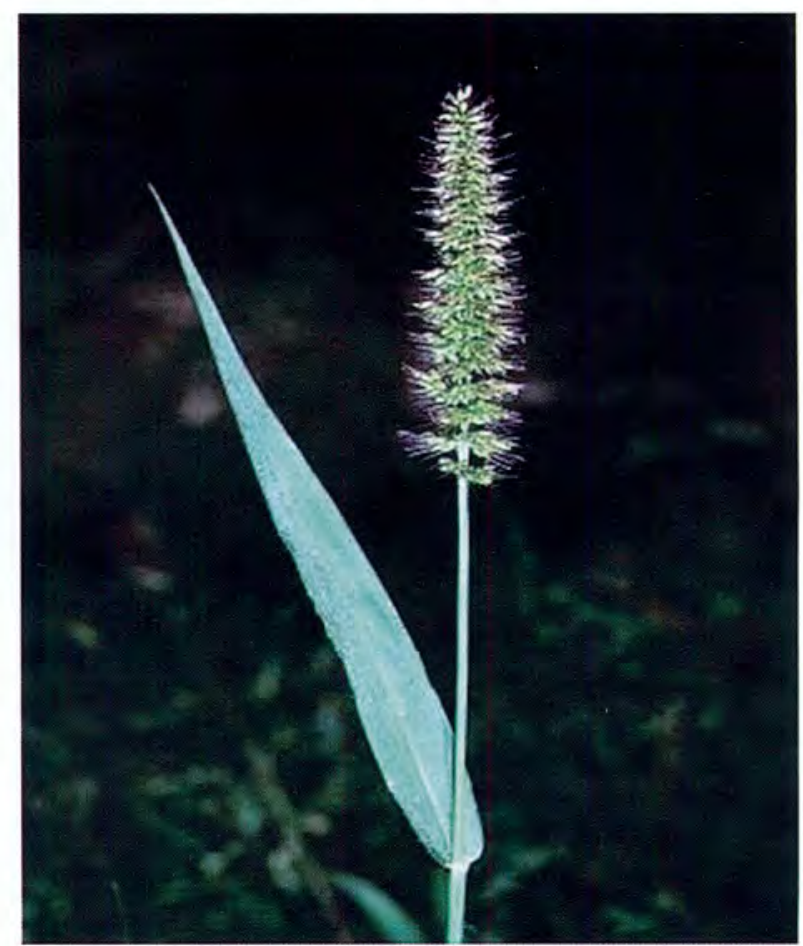

Figura 2. Setaria verticillata "Pega".

5. Setaria verticillata (L.) P.Beauv. "Pega-pega"

Especie anual. Tallos de $40-60 \mathrm{~cm}$ de alto. Láminas escabrosas en ambas superficies.

Inflorescencia en panoja espiciforme compacta. Con sedas involucrales 1-2 por espiguilla, con dentículos retrorsos que las hacen adherentes.

Fruto: Cariópside blanco grisáceo.

Origen: Europa, en la actualidad cosmopolita.

Maleza presente en cultivos de habas, arveja en el CEA III Los Pichones.

\section{b. Malezas de hoja ancha (dicotiledoneas)}

\section{FAMILIA AMARANTHACEAE}

6. Alternanthera halimifolia (Lamarck) Standley ex Pittier "Hierba blanca"

Especie perenne postrada muy ramificada. Tallos



Figura 3. Alternanthera halimifolia "Hierba blanca" 
Zegarra, R. \& Arévalo N. Malezas dominantes en los cultivos del Inprex y del centro experimental agricola (CEA) III "Los Pichones” Tacna - 2014.

puberulentos con tricomas hispidulosos. Hojas simples opuestas, oblongas, ovoides u obovado-oblongas, margen entero, de $1-4 \mathrm{~cm}$ de largo, pubescente.

Inflorescencia en espiga capituliformes, axilares, sésiles. Flores hermafroditas, blanquecinas. Brácteas y bractéolas ovadas. Tépalos ovado-oblongos. Androceo con cinco estambres. Ovario súpero.

Fruto: Utrículo obovoide.

Origen: América

Especie presente en el cultivo de vid, en el INPREX. Usos: Ornamental.

7. Alternantherapubiflora (Benth.) Kuntze "Hierba blanca".

Herbácea, erguida o procumbente de $40-60 \mathrm{~cm}$ de altura. Ramas conspicuamente pilosas, los tricomas blanquecinos.

Hojas aovadas-lanceoladas, mucronadas, de 1,5-3 $\mathrm{cm}$ de longitud por 1-1,5 $\mathrm{cm}$ de ancho, pubescentes, los pelos adpresos y blanquecinos.

Inflorescencia capituliforme, globosa, pedunculada. Flores hermafroditas terminales o axilares, blanquecinas.

Fruto: Utrículo indehiscente protegido por los tépalos persistentes.

Origen: América

Se le observa en el cultivo de vid, en el INPREX.

\section{Amarantbus bybridus L. "Yuyo, amaranto, bledo"}

Especie anual. Tallos de $20-100 \mathrm{~cm}$ de alto, erguidos, glabros o parcialmente pubescentes en la parte superior.

Hojas simples, alternas, de $1-5 \mathrm{~cm}$ de largo, rómbicoovadas, pecíolos de 1-8 cm de largo.

Inflorescencia densa, espiciforme, de $1-10 \mathrm{~cm}$ de largo. Bracteolas de 4-6 mm, ovadas, con un largo mucrón, casi el doble de largo del perianto. Flores pequeñas monoicas.

Fruto: Capsular. Semillas lenticulares, brillantes, castaño oscuras, de $1 \mathrm{~mm}$ de diámetro.

Especie común en los cultivos.

Origen: América

Usos: Sus hojas se consumen en potajes de la sierra peruana.

Ocupa el número 14 dentro de las malezas de mayor importancia en el mundo.

\section{FAMILIA CHENOPODIACEAE}

\section{Chenopodium album L. "Quinua silvestre"}

Hierba anual, vigorosa, erecta y ramosa de $0,50-1 \mathrm{~m}$ de altura, de color verde pálido y finamente farinosa.

Hojas pecioladas, ovado-lanceoladas o lanceoladas romboidales, a menudo someramente trilobadas, sinuoso dentadas, agudas, verde en la cara superior y algo pruinosas en la cara inferior, de 2-6 $\mathrm{cm}$ de largo.

Inflorescencia en panojas de glomérulos racimosos, largas y abiertas o pequeñas y densas. Flores con 5 sépalos cóncavos, glabros. Corola ausente. Estambres 5.Estigmas 2.

Semillas lenticulares, negras, liso brillante.

Origen: Europa.

Especie invasora en cultivos de hortalizas y frutales.

Ocupa el décimo lugar dentro de las malezas más importantes del mundo.

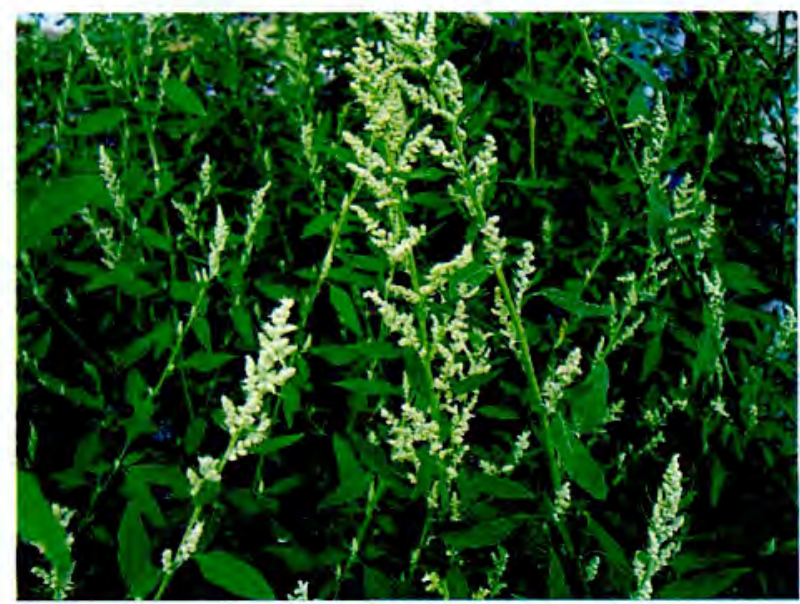

Figura 4. Chenopodium album" "Quinua silvestre"

\section{Chenopodium ambrosioides L. "Paico"}

Especie anual o bienal, aromática, erguida o ascendente, de $30-60 \mathrm{~cm}$ de alto. Hojas simples, alternas, pecioladas oblongas a lanceoladas, las inferiores sinuado-dentadas, las superiores enteras.

Inflorescencia: Axilar o panoja terminal. Flores sésiles. Perigonio glanduloso 3-5-fido.

Fruto: Envuelto por el perianto. Semillas lenticulares negras, brillantes y lisas

Origen: América tropical y subtropical.

Presente en poca cantidad en los cultivos del INPREX.

Usos: Medicinal. Condimenticia.

\section{Chenopodium murale L. "Hierba del gallinazo"}

Planta anual de olor desagradable. Tallos de 30-80 $\mathrm{cm}$ de altura, erguidos ramificados desde la base.

Hojas simples, alternas de $1,5-8 \mathrm{~cm}$ de largo romboovoides, margen dentado, haz brillante, envés pruinoso.

Inflorescencia: Panojas de glomérulos. Flores pequeñas. Sépalos 5.Corola ausente. Estambres 5.

Fruto cubierto por los sépalos, pericarpio algo transparente. Semillas lenticulares.

Origen: Asia menor

Especie invasora frecuente en los cultivos de hortalizas y frutales, en el CEA III Los Pichones y el INPREX.

\section{FAMILIA PORTULACACEAE}

\section{Portulaca oleracea L. "Verdolaga"}

Especie anual. Postrada, tallos de $10-30 \mathrm{~cm}$. de largo. Ramificados.

Hojas simples alternas en la base y opuestas bajo las flores espatuladas u oblongo, ovadas, ápice obtuso, base cuneada, margen entero, carnosas brillantes.

Flores solitarias axilares o reunidas en el ápice de las ramas o axilas de las hojas. Cáliz con dos sépalos aquillados, corola 5 pétalos de color amarillo. Estambres de 7-12. Gineceo con ovario súpero.

Fruto: Pixidio, con numerosas semillas de color negro, brillantes. 
Zegarra, R. \& Arévalo N. Malezas dominantes en los cultivos del Inprex y del centro experimental agrícola (CEA) III "Los Pichones" Tacna - 2014

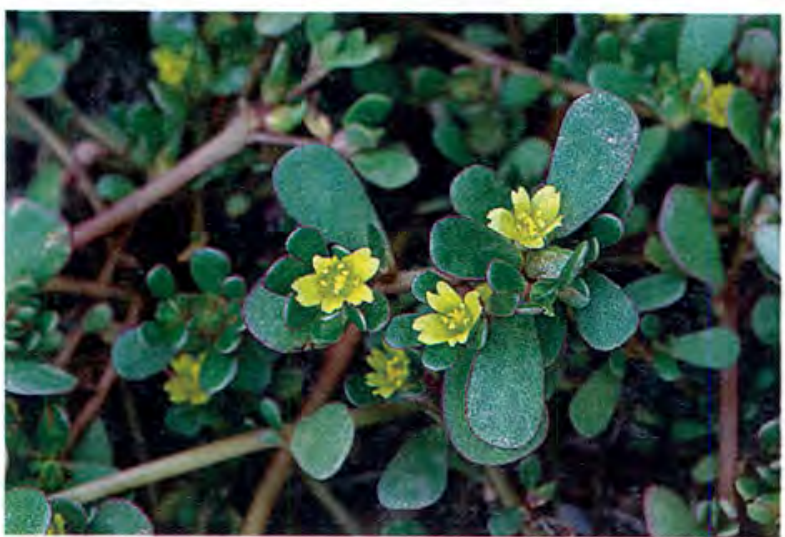

Figura 5. Portulaca oleracea "Verdolaga"

Especie muy frecuente en cultivos de arveja, habas. palta, en cultivos del CEA III Los Pichones, y en el INPREX.

Originaria de la India.

Ocupa el noveno lugar dentro de las malezas más importantes del mundo.

En paises europeos, las hojas de ésta especie se consumen en ensaladas.

\section{FAMILIA MALVACEAE}

\section{Malva parviflora L. "Malva común"}

Especie herbácea. Tallos de $30-75 \mathrm{~cm}$ de alto, con tricomas estreilados. Hojas simples, alternas, largamente pecioladas, 5-7 lóbulos poco profundos, de borde crenadodentado, con tricomas estrellados.

Inflorescencia: Flores agrupadas en número de 2-4, axilares. Calículo formado por tres bractéolas linearlanceoladas. Cáliz acrescente, con 5 sépalos orbicularestriangulares. Corola 5 pétalos de color azul liliáceo pálido. Androceo monadelfo. Gineceo con ovario súpero.

Fruto: Esquizocarpo con 9-11 mericarpos. Semillas reniformes, glabras, castaños negruzco,

Nativa de la región Mediterránea.

Especie medicinal.

Especie frecuente en cultivos de palto, arveja, habas en el CEA III Los Pichones.

\section{FAMILIA FABACEAE}

14. Melilotus albus Desr. "Trébol blanco" "Trébol de olor" "Trébol dulce"

Especie anual o bianual, hasta de $1,50 \mathrm{~cm}$ de alto .Hojas trifoliadas, con estípulas enteras subuladas. Folíolos obovados a oblongos.

Inflorescencia: Flores hermafroditas de color blanco agrupadas en largos racimos pedunculados. Cáliz acampanado, con 5 sépalos denticulados triangulares. Corola papilionácea. Androceo formado por estambres diadelfos. Gineceo con ovario súpero unicarpelar.

Fruto: Legumbre corta, globosa, oval o elíptica. Con una o dos semillas elípticas.

Nativa de Europa y Asia.

En cultivo del olivo. INPREX.

\section{Melilotusindicus (L.) All. "Trébol amarillo"}

Especie anual. Tallo hasta $50 \mathrm{~cm}$ de alto, piloso. Hojas trifoliadas. Estípulas triangulares-lanceoladas, de margen entero. Folíolos lanceolados-oblongos, de margen aserrado.

Inflorescencia: Racimos de 3-5 cm densos. Flores de color amarillo. Cáliz con 5 dientes triangulares largos. Corola papilionácea, el estandarte es más largo que las alas y la quilla. Androceo diadelfo. Gineceo con ovario súpero.

Fruto: Legumbre apiculada. Con una o dos semillas.

Origen: Europa, norte de África.

En cultivo de olivo-INPREX.

\section{FAMILIA EUPHORBIACEAE}

\section{Chamaesyce birta (L.) Millsp. "Lechera"}

Herbácea anual. Laticífera. Tallos pequeños hasta 30 $\mathrm{cm}$ de alto, erguidos o decumbentes.

Hojas simples, de $4 \mathrm{~cm}$ de largo, opuestos, rómbicolanceolado.

Inflorescencia en ciatos numerosos, agrupados en densas cimas.

Fruto: Cápsula ovoide estrigosa, amarillenta.

Semillas subprismáticas con suaves depresiones.

Origen: Pantropical.

Escasa, se le encontró en cultivo de vid.

\section{Chamaesyce bypericifolia (L.) Millsp. "Lechera"}

Especie perenne. Laticifera. Tallos hasta $30 \mathrm{~cm}$ de alto, erguidos, pubescentes.

Hojas simples de 1-2,5 cm de largo, oblongas.

Inflorescencia: Ciatos en cimas corimbosas.

Fruto: Cápsula ovoide, híspido amarillenta. Semillas globosas prismáticas, brevemente rugosas.

Nativa de América.

Especie invasora frecuente en cultivo de vid.

\section{Chamaesyce serpens (Kunth) Small "Lechera"}

Planta anual adosada al suelo, de color verde o rojizo. Tallos postrados, los cuales arraigan en los nudos donde el vástago entra en contacto con la tierra. Hojas simples, opuestas pequeñas, asimétricas, ovoide-elípticas. Casa hoja mide menos de $1 \mathrm{~cm}$ de largo.

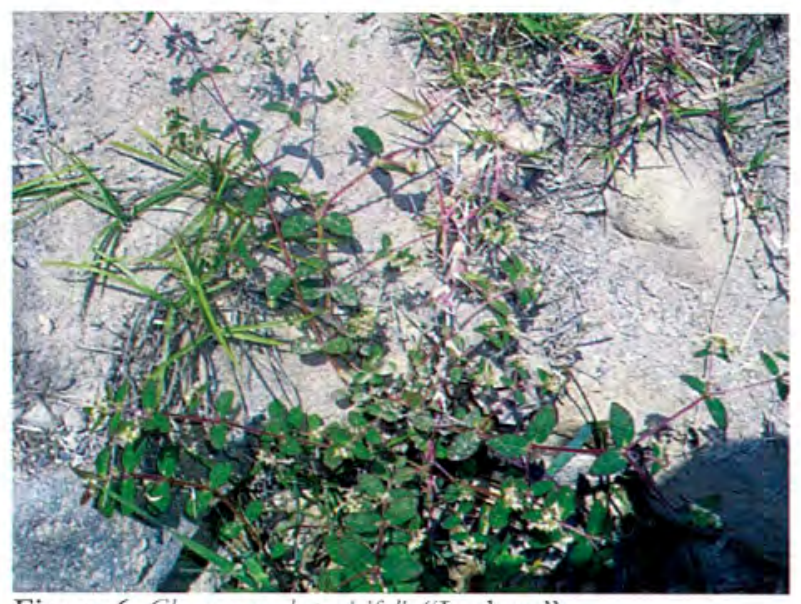

Figura 6. Chamaesyce bypericifolia "Lechera" 
Inflorescencia: Ciatos axilares y solitarios, con apéndices blancos que rodean a la verdadera flor. Glándula nectarífera de color rojo. En el centro del ciato se encuentran las flores masculinas que rodean a la flor femenina.

Fruto: Cápsula esférica lobulada.

Frecuente en cultivos de hortalizas y frutales.

\section{FAMILIA OXALIDACEAE}

\section{Oxalis corniculata L. "Trébol" "Vinagrillo"}

Especie perenne rizomatosa. Tallos rastreros pubescentes. Hojas compuestas trifoliadas. Folíolos obcordados pubescentes.

Inflorescencia cimosa umbeliforme. Flores hermafroditas actinomorfas. Sépalos 5 lanceolados. Corola amarillo pálido con pétalos oblongos. Androceo, 10 estambres. Gineceo con ovario súpero pentacarpelar.

Fruto: Cápsula linear cilíndrica pubescente. Semillas planas transversalmente rugosas.

Origen: Nativa de Europa.

Poco frecuente en cultivos del INPREX.

\section{FAMILIA SOLANACEAE}

\section{Nicandraphysalodes (L.) Gaertner "Falso capuli"}

Especie anual. Tallos de $10-50 \mathrm{~cm}$ de alto.

Hojas simples alternas de $4-10 \mathrm{~cm}$ de largo, elípticaslanceoladas, ápice agudo u obtuso, base cuneada, margen dentado o irregularmente sinuado-aserrado, penninervias.

Flores solitarias axilares, pedicelos $1-2,5 \mathrm{~cm}$ de largo. Cáliz acrescente, dividido casi hasta la base, con dientes ovados. Corola rotácea, con pétalos azules o liliáceos, blancos en la base. Estambres 5, insertos en la base de la corola. Gineceo con ovario súper bicarpelar.

Fruto: Baya seca globosa de color café

Presente en cultivos de arveja, rocoto.

Nativa de Perú.

\section{Solanum nigrum L. "Hierba mora"}

Hierba anual de $30-80 \mathrm{~cm}$ de alto, ramosa, ramas ascendentes.

Hojas simples, alternas, pecioladas, lanceoladaselípticas, ápice agudo o acuminado, base asimétrica, margen

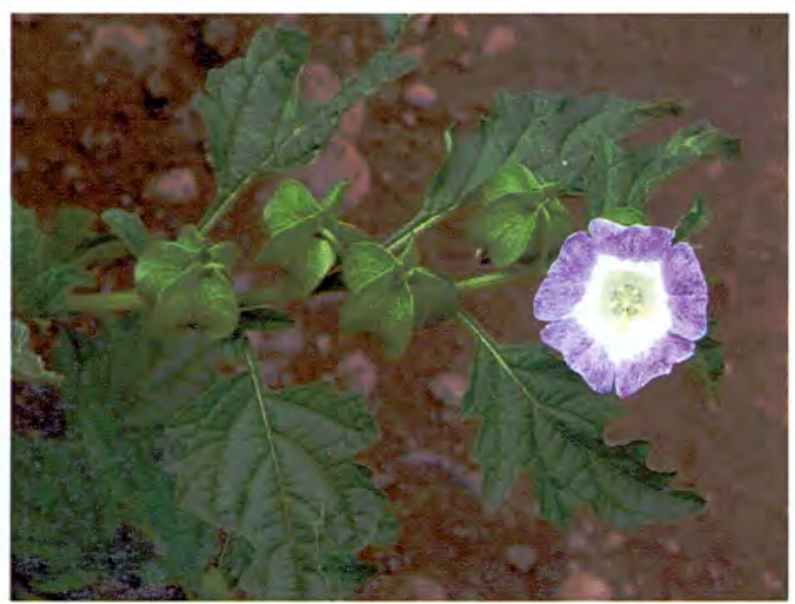

Figura 7. Nicandraphysalodes "Falso capuli"



Figura 8. Solanum nigrum "Hierba mora"

entero o un poco aserrado, penninervias, haz glabro, envés hispídulo, luego glabrescente.

Inflorescencia en umbela. Flores cortamente pediceladas. Cáliz pequeño con lóbulos inconspicuos. Corola rotácea con pétalos blancos. Estambres 5 conniventes, filamentos cortos, anteras más grandes.

Fruto: Baya esférica, negruzca. Con semillas numerosas. Se le encuentra en los cultivos de arvejas, habas, rocoto. Especie cosmopolita.

\section{FAMILIA BORAGINACEAE}

22. Heliotropium curassavicum L. "Jaboncillo, Heliotropo"

Planta perenne postrada. Ramas postradas suculentas, de $20-40 \mathrm{~cm}$ de largo, glabras y glaucas.

Hojas simples, alternas, subsésiles, semisuculentas glaucas de 13-23 mm de longitud, oblongo-lanceoladas u obovadas.

Inflorescencia: Cima unípara escorptiodea, axilares y terminales. Flores pequeñas de color blanco.

Fruto: Globoso, glabro, formado por cuatro clusas uniseminadas.

Especie invasora frecuente en suelos árido-salinos.

\section{FAMILIA VERBENACEAE}

\section{Castelia cuneato ovata Cav. "Papilla"}

Especie perenne, raíces profundas reservantes. Tallos de $15-50 \mathrm{~cm}$ de alto, erguidos, cuadrangulares, finamente pubescentes. Hojas simples, opuestas, ovoides u 
Zegarra, R. \& Arévalo N. Malezas dominantes en los cultivos del Inprex y del centro experimental agrícola (CEA) III "Los Pichones" Tacna - 2014.



Figuro 9. Heliotropium curassavicum "Jaboncillo"

ovoides-elípticas, margen dentado.

Inflorescencia: Racimos terminales. Flores hermafroditas, cigomorfas. Cáliz gamosépalo 5-dentado. Corola blanco violácea, bilabiada. Androceo con 4 estambres di dínamos, epipétalos. Gineceo con ovario súpero bicarpelar.

Fruto: Drupáceo. Semillas lisas, subcilíndricas, blancas.

Origen: América del Sur.

Presente en cultivos del INPREX.

Maleza difícil de erradicar.

Se le encuentra en cultivos del INPREX.

Especie medicinal.

\section{FAMILIA ASTERACEAE}

\section{Galinsoga parviflora Cav.}

Planta anual. Tallos $10-80 \mathrm{~cm}$ de alto, ramificados desde la base, glabros o pilosos.

Hojas simples, opuestas, trinervadas, pecíolo de 3-15 mm de largo, lámina de 1-10 cm de largo, ovoide a ovoidelanceolada, margen aserrado.

Inflorescencia en capítulo, numerosos pequeños, largamente pedunculados. Flores dimorfas, las marginales 4 5 blancas. Flores centrales amarillas, hermafroditas. glabro.

Fruto en aquenio ovoideo, medio pubescente o casi

Se le observa en el cultivo del olivo.

25. Conyza bonariensis (L.) Cronq. "Foquitos"

Anual. Tallos 40-100 cm de largo, densamente pubescentes, ramificados en la parte superior.

Hojas simples. La especie presenta dimorfismo foliar. Las hojas inferiores oblanceoladas, las superiores lineares o linear-lanceoladas, pubescentes.

Capítulos numerosos. Flores dimorfas. Los semiflósculos numerosos con tubos filiformes, cortamente liguladas. Flores centrales tubulosas en menor número.

Fruto: Aquenio, oblongo, aplanado.

Especie invasora del cultivo de olivo.

\section{Bidenspilosa L. "Chiriro, amor seco"}

Anual. Tallos $30-100 \mathrm{~cm}$ de alto erguidos, ramificados, glabros o pilosos.

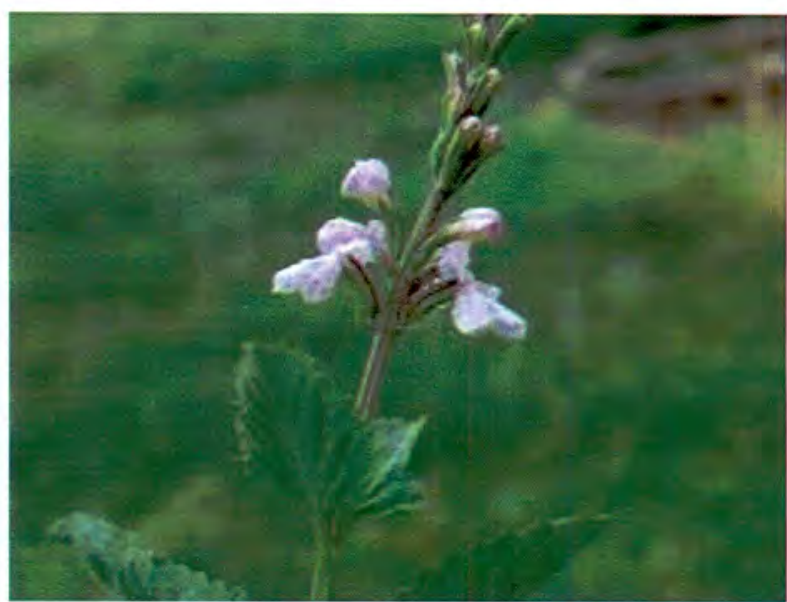

Figura10. Castelia cuneato ovata "Papilla"

Hojas simples, opuestas, pinnatisectas.

Capítulos largamente pedunculados Flores dimorfas, los semiflósculos ligulados ausentes o presentes, de color blanco o amarillo. Las flores centrales, tubulosas amarillas.

Aquenios lineares, rectos, cubiertos de cerdas antrorsas. Pappus formado por 2-3 Frecuente en el cultivo de olivo.

\section{Sonchus asper (L.) J.Hill "Janacho, Cerraja"}

Especie anual .Laticífera. Tallos de 10-1m de altura, erguido, a veces ramificado.

Hojas simples, de 5-15 cm de largo.La especie presenta dimorfismo foliar. Las hojas inferiores espatuladas, enteras a pinnatífidas, las superiores enteras a pinnatisectas.

Inflorescencia en capítulo. Con flores liguladas, amarillas más corta que el tubo.

Fruto: Aquenio aplanado, con el pappus piloso.

Especie frecuente en los cultivos.

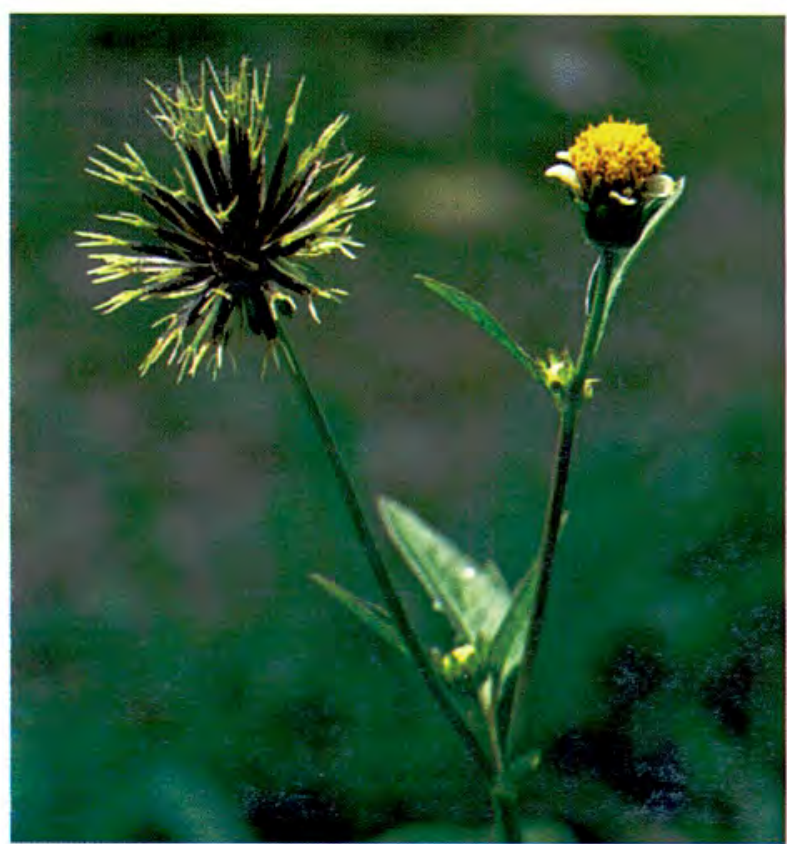

Figura 11. Bidenspilosa"Chiriro" 
Zegarra, R. \& Arévalo N. Malezas dominantes en los cultivos del Inprex y del centro experimental agrícola (CEA) III "Los Pichones" Tacna - 2014.

28. Sonchus oleraceus L. "Janacho, Cerraja"

Anual. Laticíferas. Tallos de $20-1,20 \mathrm{~cm}$ de altura, erguidos, glabros, huecos.

Hojas simples, de $5-15 \mathrm{~cm}$ de largo. Las basales ovoides, pecioladas, las superiores pinnatífidas, base auriculada.

Inflorescencia en capítulo con flores liguladas, amarillas.

Fruto: En aquenio, aplanados, oblanceolados. Con el pappus piloso.

Especie invasora menos frecuente que la especie anterior.

\section{DISCUSIÓN}

El número de malezas son el resultado de la supervivencia y reproductividad de las semillas en un momento determinado.

La comunidad de malezas en los lugares estudiados, estaba representada por veintitrés especies de hoja ancha (Dicotiledóneas) y cinco de hoja angosta (Monocotiledóneas), siendo la de mayor predominancia las de Hoja Ancha. La Monocotiledónea, dominante fue Cynodon dactylon "Grama dulce", en cambio las Dicotiledóneas más abundantes fueron: Amaranthus bybridus "Yuyo", Portulaca oleracea "Verdolaga" y Malva parviflora"Malva".

Según Alave (2011) y Palomino (2010), tuvieron que erradicar las malezas, presentes en los cultivos de vid y tomate mediante deshierbo.

De las dieciocho malezas más importantes del mundo según Holm (1977), cinco se encuentran en los lugares estudiados y son: Cyperus rotundus "Coquito" (1' lugar), Cynodon dactylon "Grama dulce" ( $2^{\circ}$ lugar), Portulaca oleraced "Verdolaga " ( $9^{\circ}$ lugar), Chenopodium álbum "Quinua silvestre" (10 lugar) y Amaranthus bybridus "Yuyo" (14 lugar).

\section{CONCLUSIONES}

En el INPREX y CEA III Los Pichones, se han encontrado veintiocho tipos de malezas en los cultivos de diferentes especies vegetales instalados en el CEA III Los Pichones y en el INPREX tales como: Vid, olivo y durazno, palto, arveja, orégano, maíz, habas, vainita, rocoto.
De las veintiocho especies, cinco corresponden a malezas de hoja angosta (Monocotiledóneas) y veintitrés a malezas de hoja ancha (Dicotiledóneas).

Las familias con mayor número de especies son: Asteráceas y Poáceas, con cinco y cuatro especies respectivamente.

De las veintiocho especies señaladas, algunas tienen diferentes usos: Medicinales: Malva parviflora "Malva", Chenopodium ambrosioides "Paico". Comestibles: Amaranthus bybridus, "Yuyo" en la sierra peruana", Portulaca oleracea "Verdolaga", en países europeos. Fijadoras de suelos: Cynodon dactylon "Grama dulce-Pata de gallina". Forrajeras: Cynodon dactylon "Grama china-Pata de gallina", Bromus catharticus "Cebadilla".

\section{REFERENCIAS BIBLIOGRÁFICAS}

Alave, W. (2011). Niveles de fertilización nitrogenada y potásica en el rendimiento de vid (Vitis vinifera L.) $\mathrm{cv}$. Cabernet Sauvignon en el INPREX (tesis de pregrado). Facultad de Ciencias Agrícolas. UNJBG.

Doll J. (1986). Manejo y control de malezas en el trópico. Centro Internacional de Agricultura Tropical. Colombia.

Helfgott, S. (1981). Control de malezas. Lima-Perú: Biblioteca Agropecuaria del Perú.

Holm, L.G. et al., (1977). The world's worst weeds, distribution and biology. Hawai: The University press of Hawai, Honolulu.

Matthei, O. (1995). Manual de las malezas que crecen en Chile. Santiago de Chile.

Mederos, D. (2004). Curso de malezas y su manejo. La HabanaCuba.

Palomino, O. (2010). Comparativo de rendimiento de cuatro híbridos de tomate Lycopersicon esculentum Mill. en el CEA III Los Pichones-Tacna (tesis de pregrado). Facultad de Ciencias Agrícolas. UNJBG.

Sagástegui, A. (1993). Flora invasora de los cultivos del Perí. Trujillo-Perú.

Zegarra, R. (1996). Malezas no halófitas del extremo sur del Perú. Revista Ciencia er Desarrollo, 04.
Correspondencia:

Rosario Zegarra Zegarra: rosariozegarra13@hotmail.com
Fecha de Recepción: 27/09/2015

Fecha de Aceptación: 05/12/2015 